\title{
Comparative Analysis of Shoulder Balance through Growth Guidance Techniques in the Surgical Treatment of Early-onset Scoliosis
}

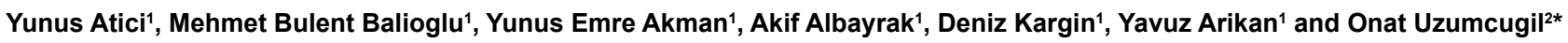

${ }^{1}$ Metin Sabanci Baltalimani Bone Diseases Training and Research Hospital, Department of Spine Surgery, Istanbul, Turkey

${ }^{2}$ Istanbul Kemerburgaz University, School of Medicine, Department of Orthopaedics and Traumatology, Istanbul, Turkey

\begin{abstract}
Objective: The purpose of this study was to compare the efficacy of growth guidance techniques (single and dual growing rods, Vertical Expandable Prosthetic Titanium Rod-VEPTR) on shoulder balance, in the surgical treatment of early-onset scoliosis.
\end{abstract}

Methods: Thirty six patients with early-onset scoliosis (EOS) due to various etiologies who were operated on in two different institutions were included in the study and they were divided in 3 groups. Group 1 consisted of 11 patients (mean age 7.5 years) who were treated with a single growing rod, Group 2 had 13 patients (mean age 8.1 years) who were treated with dual growing rods, and Group 3 consisted of 12 patients (mean age 4.1 years) who were treated with VEPTR technique. The coracoid height difference (CHD), clavicular tilt angle difference (CTAD) and clavicula-rib cage intersection difference (CRID) were measured on standing anteroposterior X-ray images in the preoperative, early postoperative and the last follow-up periods. Data obtained from these measurements were subject to statistical analysis.

Results: The average postoperative follow up period was 3.04 (range: 2.3 to 4.8 ) years for Group 1, 2.23 (range: 1 to 3.1) years for Group 2 and 2.18 (range: 1 to 3.2) years for Group 3. Clinical improvement in shoulder balance was obtained for Group 1 and Group 2 post-operatively, but there was no significance in the comparison among the three groups.

Conclusion: The effect of growth guidance techniques on shoulder balance remains unpredictable in the surgical treatment of early-onset scoliosis.

Keywords: Growing rod; VEPTR; Early onset scoliosis; Shoulder balance

\section{Introduction}

While making surgical decisions regarding cosmesis for the treatment of scoliosis, in addition to the spine's coronal balance also shoulder balance is one of the most important criteria to be estimated [1]. The effect of growth guidance techniques on shoulder balance is temporary, and these techniques may play a role in establishing shoulder balance in the final fusion stage. Some surgeons may prefer to leave the patients with the implants that are used to perform growth guidance techniques, without performing the final fusion surgery [2]. Thus, with the use of growth guidance techniques, when the final fusion is not performed at the end of the lengthening period, the shoulder balance attained following the lengthening period gains greater importance.

The aim of this retrospective study was to evaluate the effects of the three distinct growth guidance techniques on shoulder balance in the coronal-plane, by measuring the following radiographical parameters of shoulder balance (difference of coracoid process height-CHD, clavicula-tilt angle-CTAD and clavicula-rib cage intersection pointCRID) [3-5] that were obtained in the preoperative, postoperative and final follow-up period which underwent statistical analysis in comparison with each other.

\section{Materials and Methods}

Thirty six patients with EOS due to various etiologies were operated on between the years 2004-2011 at two different institutions. Three different non-fusion techniques (single growing rod, dual growing rod, VEPTR) were performed. For all three groups, rod extensions were applied periodically. Group 1 consisted of 11 patients who were treated with single rod technique, where the side-to-side submuscular connector was placed on the concave side of the major curve. In Group
2 , the dual rod technique was performed in 13 patients, where the sideto-side submuscular connectors were placed on both sides of the major curve. Finally Group 3 consisted of 12 patients who were treated with VEPTR technique, in which the implant was applied on the concave side of the major spinal curve.

In Group 1, there were 8 female and 3 male patients and the average age at the beginning of the treatment was 7.45 (range: 6 to 9) years. Group 2 consisted of 11 female and 2 male patients and the average age at the beginning of the treatment was 8.1 (range: 5 to 11) years. There were 7 female and 5 male patients in Group 3 and the average age was 4.1 (range: 1.6 to 9) years at the beginning of the treatment. Final fusion surgery was performed in 6 of the 11 patients in Group 1, in 5 of the 13 patients in Group 2 and in one of the 12 patients in Group 3. Demographic characteristics can be seen in Table 1 .

The lengthening procedures were performed in 6 to10 months' intervals. The numbers of distractions were noted for all three groups.

The radiological evaluation was performed on standardized lateral and posteroanterior $\mathrm{X}$-ray images obtained in the preoperative, in the early postoperative and during the last follow-up periods (Figures 1-3). Cobb's

*Corresponding author: Onat Uzumcugil, Istanbul Kemerburgaz University, School of Medicine, Medical Park Bahcelievler Hospital, Kultur Sok. No: 1, Bahcelievler/ Istanbul, Turkey, Tel: +905335220459; E-mail: onat.dr@gmail.com

Received November 10, 2013; Accepted December 10, 2014; Published December 12, 2014

Citation: Atici Y, Balioglu MB, Akman YE, Albayrak A, Kargin D, et al. (2014) Comparative Analysis of Shoulder Balance through Growth Guidance Techniques in the Surgical Treatment of Early-onset Scoliosis. J Spine 4: 201. doi: 10.4172/2165-7939.1000201

Copyright: (c) 2014 Atici Y, et al. This is an open-access article distributed under the terms of the Creative Commons Attribution License, which permits unrestricted use, distribution, and reproduction in any medium, provided the original author and source are credited. 
Citation: Atici Y, Balioglu MB, Akman YE, Albayrak A, Kargin D, et al. (2014) Comparative Analysis of Shoulder Balance through Growth Guidance Techniques in the Surgical Treatment of Early-onset Scoliosis. J Spine 4: 201. doi:10.4172/2165-7939.1000201

Page 2 of 4

\begin{tabular}{|l|c|c|c|}
\hline & $\begin{array}{c}\text { GROUP 1 } \\
\text { Single growing rod }\end{array}$ & $\begin{array}{c}\text { GROUP 2 } \\
\text { Dual growing rod }\end{array}$ & $\begin{array}{c}\text { GROUP 3 } \\
\text { VEPTR }\end{array}$ \\
\hline Number of patients & 11 & 13 & 12 \\
\hline Age & 7.5 & 8.1 & 4.1 \\
& $(6-9)$ & $(5-11)$ & $(1.6-8)$ \\
\hline Follow-up period & 3.04 & 2.23 & 2.18 \\
& $(2.3-4.8)$ & $(1-3.1)$ & $(1-3.2)$ \\
\hline Average number of & 5.4 & 4.1 & 4 \\
distractions & $(3-6)$ & $(2-7)$ & $(2-5)$ \\
\hline & & 3 congenital & 6 congenital \\
Diagnosis & 1 congenital & 2 syndromic & 1 neuromuscular \\
& 10 idiopathic & 8 idiopathic & 3 idiopathic \\
\hline
\end{tabular}

Table 1: Patient Demographics.

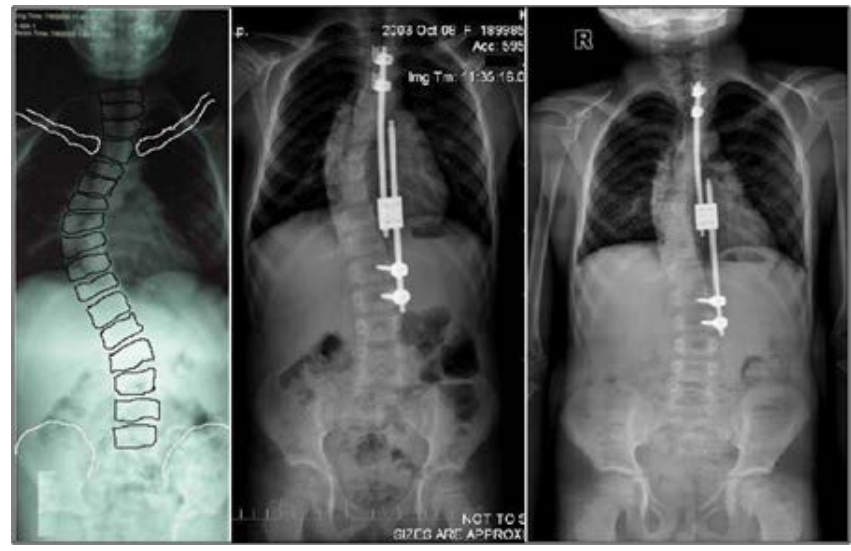

Figure 1: Posteroanterior X-ray images of a patient from Group 1 obtained in the preoperative, early postoperative periods and during the last follow-up period.
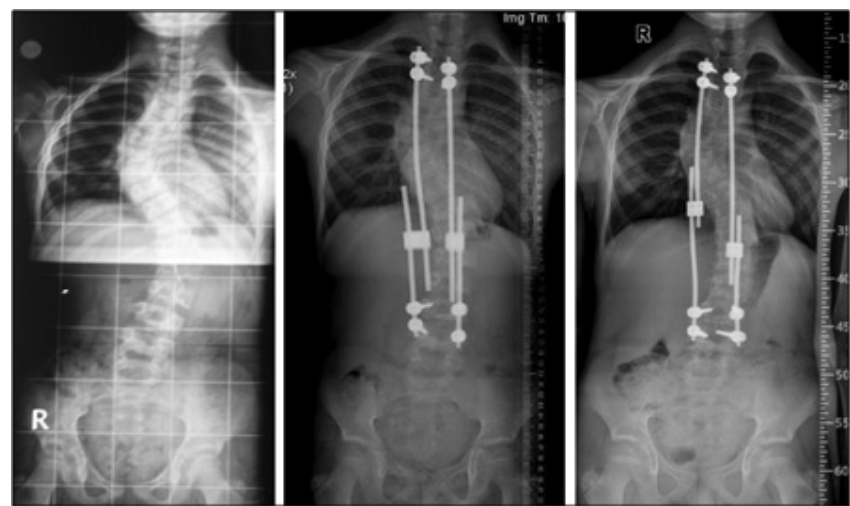

Figure 2: Posteroanterior X-ray images of a patient from Group 2 obtained in the preoperative, early postoperative periods and during the last follow-up.

angle of the main curve, shoulder balance (CHD, CTAD and CRID), coronal balance were measured on the radiographies. Comparison of the preoperative, postoperative and last follow-up coronal plane parameters of the three groups are listed in Table 2.

Coracoid height difference (CHD) was calculated by measuring the distance between the horizontal lines drawn through the superior aspects of the both coracoid processes. Clavicle-rib cage intersection difference (CRID) is known as the distance between the horizontal lines drawn through the intersecting points of the superior aspects of each clavicle with the outer edge of the second rib's insertio (Figure 4) [3-5]. The clavicular tilt angle difference (CTAD) is the difference between the angles formed by the bisection of the lines of the proximal portions of the clavicle with the horizontal (Figure 4) [4].

The patient was classified as shoulder imbalanced if $\mathrm{CHD}$ was more than $9 \mathrm{~mm}$ and/or CTAD was more than $4.5^{\circ}$ and/or CRID was more than $7.1 \mathrm{~mm}$ (Figure 4) [4]. The measurements that are expressed in millimeters were calibrated according to the scale on the digital X-ray images.

\section{Complications were noted.}

Demographic and radiographical data of the groups were analysed statistically using computer software (PASW ver. 15.0; SPSS). Mann-Whitney $U$ test and Kruskal-Wallis test were used $(\mathrm{P}<0.05$ was significance set value) for the analysis of the parameters of age, lengthening numbers, follow-up time and lengthening intervals. To compare sex and other categorical data, Pearson Chi-Square test was performed. CHD, CTAD, CRID, main curve and coronal balance values for each group were analyzed using Friedman test and Pillai Trace $(\mathrm{P}<0.05$ was significance set value). Bonferroni test was used for the comparison of radiological data among the 3 groups $(\mathrm{P}<0.05$ was significance set value).

\section{Results}

The average follow-up periods for Group 1, Group 2 and Group 3 was 3.04 (range: 2.3 to 4.8 ) years, 2.23 (range: 1 to 3.1 ) years and 2.18 (range: 1 to 3.2 ) years respectively (Table 1 ).

The average numbers of distractions for Group 1, Group 2 and Group 3 were 5.4 (range: 4 to 6), 4.1 (range: 2 to 7), and 4 (range: 2 to 5) respectively (Table 1). For Group 1, the average preoperative CHD was 14.3 (range: 2 to 38 ) $\mathrm{mm}$, the average early postoperative CHD was 11.9 (range: 0 to 38 ) $\mathrm{mm}$, and the average last follow-up period CHD was 9.6 (range: 0 to 35) $\mathrm{mm}$ ( $\mathrm{p}>0.05$ ). For Group 2, the average preoperative CHD was 15.9 (range: 2 to 35 ) $\mathrm{mm}$, the average early postoperative CHD was 12.2 (range: 2 to 30$) \mathrm{mm}$, and the average last follow-up period CHD was 15.1 (range: 0 to 35 ) $\mathrm{mm}$ ( $\mathrm{p}>0.05$ ). For Group 3, the average preoperative CHD was 16.2 (range: 2 to 37 ) $\mathrm{mm}$, the average early postoperative CHD was 13.1 (range: 4 to 30 ) $\mathrm{mm}$, and the average last follow-up period CHD was 16.7 (range: 2 to 50) $\mathrm{mm}$ ( $\mathrm{p}>0.05)$ (Table 2).

For Group 1, the average preoperative CTAD was $12.4^{\circ}$ (range: $0^{\circ}$ to $24^{\circ}$ ), the average early postoperative CTAD was $7.5^{\circ}$ (range, $0^{\circ}$ $22^{\circ}$ ), and the average last follow-up period CTAD was $8.5^{\circ}$ (range: $0^{\circ}$ to $\left.31^{\circ}\right)(\mathrm{p}>0.05)$. For Group 2, the average preoperative CTAD was $10.6^{\circ}$ (range: $1^{\circ}$ to $21^{\circ}$ ), the average early postoperative CTAD was $8.2^{\circ}$ (range: $0^{\circ}$ to $23^{\circ}$ ), and the average last follow-up period CTAD was a $6.9^{\circ}$ (range: $1^{\circ}$ to $\left.20^{\circ}\right)(\mathrm{p}>0.05)$. For Group 3, the average preoperative CTAD was $11^{\circ}$ (range: $3^{\circ}-24^{\circ}$ ), the average early postoperative CTAD was $8^{\circ}$ (range: $1^{\circ}-25^{\circ}$ ), and the average last follow-up period was $13.5^{\circ}$ (range: $2^{\circ}$ to $\left.40^{\circ}\right)(\mathrm{p}>0.05)$ (Table 2$)$.

In Group 1, the average preoperative CRID was 10.9 (range: 3 to $25) \mathrm{mm}$, the average early postoperative CRID was 7.2 (range: 0 to 20) $\mathrm{mm}$, and the average last follow-up period CRID was 8.7 (range: 1 to 22) $\mathrm{mm}(\mathrm{p}>0.05)$. In Group 2, the average preoperative CRID was 10.3 (range: 1 to 30 ) $\mathrm{mm}$, the average early postoperative was 7.4 (range: 0 to 30) $\mathrm{mm}$, and the average last follow-up period was 11.3 (range: 1 to 21) $\mathrm{mm}(\mathrm{p}>0.05)$. For Group 3, the average preoperative CRID was 11.4 (range: 1 to 36$) \mathrm{mm}$, the average early postoperative was 9 (range: 1 to 20) $\mathrm{mm}$, and the average last follow-up period was 14.4 (range: 2 to 36 ) $\mathrm{mm}(\mathrm{p}>0.05)$ (Table 2).

In the inter-group comparison there was no significant difference among the 3 groups in terms of CHD, CTAD and CRID parameters 


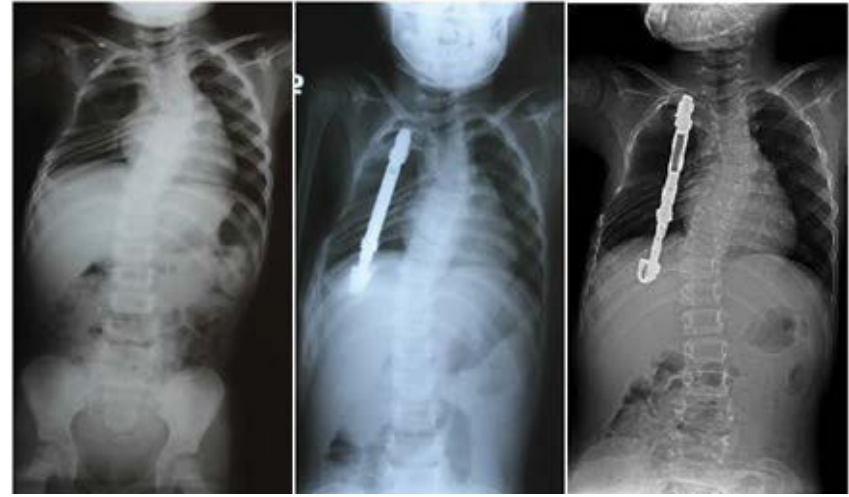

Figure 3: Posteroanterior X-ray images of a patient from Group 3 obtained in the preoperative, early postoperative periods and during the last follow-up.

\begin{tabular}{|c|c|c|c|}
\hline & & Group 2 & Group 3 \\
\hline \multirow{3}{*}{$\begin{array}{l}\text { CHD (mm) } \\
(p>0.05)\end{array}$} & Preoperative & 15.9 & 16.2 \\
\hline & Early postoperative & 12.2 & 8 \\
\hline & Last follow-up & 15.1 & 13.5 \\
\hline \multirow{3}{*}{$\begin{array}{l}\operatorname{CTAD}\left({ }^{\circ}\right) \\
(p>0.05)\end{array}$} & Preoperative & 10.6 & 11 \\
\hline & Early postoperative & 8.2 & 8 \\
\hline & Last follow-up & 6.9 & 13.5 \\
\hline \multirow{3}{*}{$\begin{array}{l}\text { CRID (mm) } \\
(p>0.05)\end{array}$} & Preoperative & 10.3 & 11.4 \\
\hline & Early postoperative & 7.4 & 9 \\
\hline & Last follow-up & 11.3 & 14.4 \\
\hline \multirow{3}{*}{ Cobb Angle $\left({ }^{\circ}\right)$} & Preoperative & 63.2 & 66.1 \\
\hline & Early postoperative & $37(p<0.05)$ & $52.1(p<0.05)$ \\
\hline & Last follow-up & $38.4(p<0.05)$ & $58.2(p>0.05)$ \\
\hline \multirow{3}{*}{$\begin{array}{l}\text { Coronal balance } \\
\qquad(\mathrm{cm})\end{array}$} & Preoperative & 2.7 & 2.18 \\
\hline & Early postoperative & $1.65(p<0.05)$ & $2.95(p>0.05)$ \\
\hline & Last follow-up & $1.56(p<0.05)$ & $3.78(p>0.05)$ \\
\hline
\end{tabular}

Table 2: Comparison of the preoperative, postoperative and last follow-up coronal plane parameters of the three groups.

\section{$(\mathrm{p}>0.05)$ (Table 2).}

The average preoperative Cobb's angle of the main curve in Group 1 was $58.5^{\circ}$ (range: $35^{\circ}$ to $80^{\circ}$ ), while the average early postoperative Cobb's angle was $37.7^{\circ}$ (range: $20^{\circ}$ to $66^{\circ}$ ), and the average Cobb's angle during the last follow-up period was $28.5^{\circ}$ (range: $16^{\circ}$ to $\left.59^{\circ}\right)(\mathrm{P}<0.05)$. In Group 2, the average preoperative Cobb's angle of the main curve was $63.2^{\circ}$ (range: $28^{\circ}$ to $114^{\circ}$ ), the average early postoperative Cobb's angle was $37^{\circ}$ (range: $7^{\circ}$ to $62^{\circ}$ ), and the average Cobb's angle measured during the last follow-up period was $38.4^{\circ}$ (range: $7^{\circ}$ to $74^{\circ}$ ) $(\mathrm{P}<0.05)$. Finally, in Group 3, the average preoperative Cobb's angle was $66.1^{\circ}$ (range: $48^{\circ}$ to $88^{\circ}$ ), the average early postoperative Cobb's angle was $52.1^{\circ}$ (range: $32^{\circ}$ to $\left.85^{\circ}\right)(\mathrm{P}<0.05)$, and the average Cobb's angle measured during the last follow-up period was $58.2^{\circ}$ (range: $40.4^{\circ}$ to $\left.96^{\circ}\right)(\mathrm{P}>0.05)$ (Table 2).

The average preoperative coronal balance in Group 1 was identified as 1.47 (range: 0 to 4 ) $\mathrm{cm}$, while the average early postoperative coronal balance was 1.44 (range: 0 to 3 ) $\mathrm{cm}$, and the average coronal balance during the last follow-up period was 1.01 (range: 0 to 2.5$) \mathrm{cm}(\mathrm{p}>0.05)$. In Group 2 the average preoperative coronal balance was 2.7 (range: 0.8 to 10$) \mathrm{cm}$, the average early postoperative coronal balance was 1.65 (range: 0 to 6.2$) \mathrm{cm}$, and the average coronal balance during the last follow-up period was 1.56 (range: 0 to 7$) \mathrm{cm}(\mathrm{p}<0.05)$. In Group 3, the average preoperative coronal balance was 2.18 (range: 0.2 to 8 ) $\mathrm{cm}$, the average early postoperative coronal balance was 2.95 (range: 0.6 to 8 ) $\mathrm{cm}$, and the average coronal balance during the last follow-up period was 3.78 (range: 0.2 to 12$) \mathrm{cm}$ ( $\mathrm{p}>0.05)$ (Table 2).

In Group 1, in 9 of the 11 patients (81.8\%) 27 complications (8.9/ year) occurred (3.71/year/patient). The complications consisted of 9 hook dislocations, 8 rod fractures, loosening in 2 upper screw caps, 2 lamina fractures, 1 screw pullout, 1 superficial wound infection, 1 paraplegia, 1 proximal junctional kyphosis and hemothorax in 2 cases. Superficial wound infection healed with parenteral antibiotics. Lamina fracture and proximal junctional kyphosis were treated conservatively. Hook and screw dislodgements were managed using 1 level above/ below the previous anchor sites by hooks/pedicle screws. Broken rods were exchanged in to new rods and after the revision lengthening continued using the same indications. Loosening screw caps were exchanged in to new screw caps after the revision lengthening.

In Group 2, in 8 of the 13 patients (61.5\%) 14 complications (6.3/ year) occurred (1.61/year/patient). These complications consisted of 4 hook displacements, 2 rod fractures, 2 screw pullouts, 2 skin infections, 1 lamina fracture, 1 deep wound infection and proximal junctional kyphosis in 2 cases. Skin infections healed with parenteral antibiotics. Deep wound infection healed with parenteral antibiotics and repeated debridement. Lamina fracture was treated conservatively. Hook and screw dislodgements were managed using 1 level above/ below the previous anchor sites by hooks/pedicle screws. Broken rods were exchanged in to new rods and after the revision lenghthening continued using the same indication.

In Group 3, in 10 of the 12 patients (83.3\%) 26 complications (11.9/year) occurred (3.62/year/patient). The complications consisted of 7 proximal cradle migrations, 5 distal laminar hook displacements, 5 deep wound infections, 3 distal cradle migrations, 2 screw pullouts, 1 lamina fracture, 1 crankshaft phenomenon, 1 skin infection, and the loosening of 1 distal McCarty rod. Skin infection healed with parenteral antibiotics. Deep wound infections healed with parenteral antibiotics and repeated debridement. Lamina fracture was treated conservatively. Hook and screw dislodgements were managed using 1 level above/below the previous anchor sites by hooks/pedicle screws. The loosening of distal McCarty rod was exchange with pedicle screw in L5. The crankshaft phenomenon devoloping VEPTR system was removed and then dual growing rod system was established instead of VEPTR. The proximal and distal cradle migrations were exchanged new 1 or 2 level above/below rib.

\section{Discussion}

In our study we used the radiological parameters to evaluate
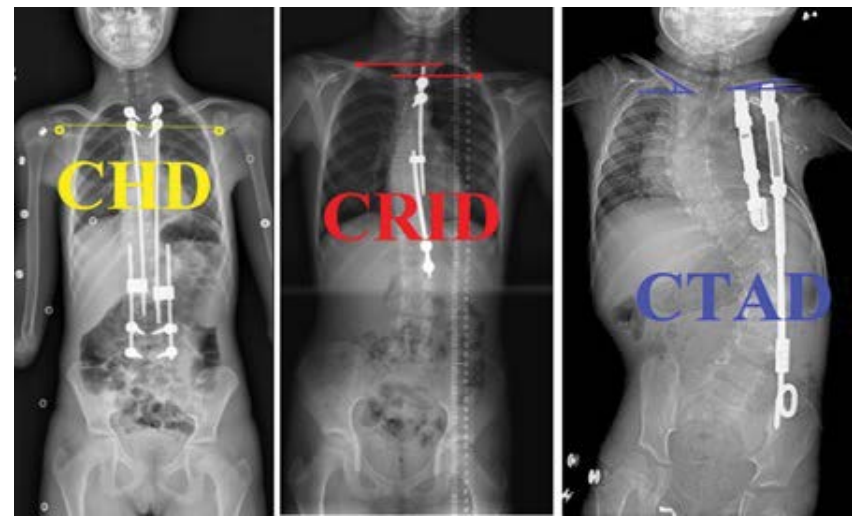

Figure 4: Measurement of radiographic shoulder balance parameters. CHD indicates coracoid height difference; CRID indicates clavicle-rib intersection difference; and CTAD indicates clavicular tilt angle difference. 
shoulder balance, because in the relevant literature the radiological parameters that are used to evaluate shoulder balance are reported to be correlated with the clinical evaluation of the shoulder $[3,4,6]$. In a study carried out by Bago et al. [3] CHD was determined to be significantly linked with the real shoulder balance. Akel et al. [4] evaluated shoulder balance of normal adolescent population evaluated both through a radiological and clinical perspective. They determined that CHD and CRID were highly correlated with the clinical evaluation parameters, while CTAD was correlated moderately. Uzumcugil et al. [7] , evaluated the shoulder balance in EOS scoliosis patients operated with a growing rod, due to various etiologies. They concluded that the CHD should be the primary parameter to be measured, as it proved to be the best method. We selected the above 3 parameters of radiology for our own evaluations of shoulder balance regarding the relevant literature. Our analysis showed that preoperative shoulder imbalance measurements were similar in all groups statistically. The single growing rod was found to be the best method by means of CHD and CRID measurements, and the dual growing rod was found to be the best method by mean of CTAD measurement to evaluate shoulder balance. However, in a comparison of all three implant groups, there was no statistically significant difference among them.

Samy et al. [8] reported that they have achieved improvement in Cobb's angle and modest intraoperative correction in shoulder balance in the patients with congenital scoliosis that were operated with VEPTR. They claimed that at the end of the follow-up period, CHD and CTAD parameters both improved significantly. In our series, 6 of the 12 patients who were treated with VEPTR had congenital scoliosis. At the end of the follow-up period, there was not a significant correction attained in Group 3. In the congenial cases, we noticed a regression in shoulder balance parameters postoperatively in Group 3. These parameters include CHD in two patients, CRID in 7 patients and CTAD in 4 patients. Uzumcugil et al. [7] published a report indicating that the single growing rod technique provided better improvement for shoulder imbalance. In our study, the single rod technique, when compared to the dual rod and VEPTR groups, provided greater improvement in shoulder imbalance, however we have found that in Group 3 there have been regression by means of shoulder imbalance.

Bess et al. [9] analyzed the complications of 140 patients treated with growing rods. The number of the complications was significantly higher in the patients treated with a single rod, than patients treated with dual rods. The correction of the curve was also found to be more significant in the dual rod group. In EOS patients treated with opening wedge thoracotomy by intercostal muscle lysis and VEPTR, Thompson et al reported 1.19 complications per patient [10]. Sankar et al. [11] pointed out that while the complication rate of patients with a dual growing rod was 2.3 per patient (average complications 0.52 /year), the complication rate of VEPTR patients was 2.37 per patient $(0.52 /$ year) which is quite high in contrast to the other studies [12-14]. The study carried out by Thompson et al. reported that the single growing rod group experienced relatively fewer complications, compared with the dual growing rod group [10]. In our study, all three implants provided significant correction of the preoperative Cobb's angle, in the early postoperative period. However, during the last follow-up, the results were significantly bad in Group 3. Surprisingly, the follow-up period showed that the single growing rod offered the most significant correction. The dual growing rod led to the fewest number of complications, while the single growing rod and VEPTR had similarly high numbers of complications.

The lack of the data on the sagittal balance parameters, less number of patients in the groups, the existence of heterogeneities especially due to various etiologies and ages of the patients and the lack of the evaluation of the estimated growth in the length of the spine in conjunction with the age of the patients in the shoulder imbalance definition may be listed as the limitations of our study.

This study's major conclusions are as follows: the single growing rod technique provided the highest rate of correction, while the dual growing rod technique led to fewer complications, relatively more spinal growth and better coronal balance. The single growing rod technique provided better improvement in CHD and CRID. The dual growing rod technique offered more improvement in CTAD. However, based on the radiological parameters we used to evaluate shoulder balance, we claim that the single rod technique can provide better results for achieving shoulder balance. For a more accurate evaluation, a study including a larger number of patients with a greater amount of homogenity is essential for a meaningful comparison.

\section{References}

1. Hong JY, Suh SW, Modi HN, Yang JH, Park SY (2013) Analysis of factors that affect shoulder balance after correction surgery in scoliosis: a global analysis of all the curvature types. Eur Spine J 22: 1273-1285.

2. Yang JS, McElroy MJ, Akbarnia BA, Salari P, Oliveira D, et al. (2010) Growing rods for spinal deformity: characterizing consensus and variation in current use. J Pediatr Orthop 30: 264-270.

3. Bagó J, Carrera L, March B, Villanueva C (1996) Four radiological measures to estimate shoulder balance in scoliosis. J Pediatr Orthop B 5: 31-34.

4. Akel I, Pekmezci M, Hayran M, Genc Y, Kocak O, et al. (2008) Evaluation of shoulder balance in the normal adolescent population and its correlation with radiological parameters. Eur Spine J 17: 348-354.

5. Qiu XS, Ma WW, Li WG (2009) Discrepancy between radiographic shoulde balance and cosmetic shoulder balance in adolescent idiopathic scoliosis patients with double thoracic curve. Eur Spine J 18: 45-51

6. Kuklo TR, Lenke LG, Graham EJ, Won DS, Sweet FA, et al. (2002) Correlation of radiographic, clinical, and patient assessment of shoulder balance following fusion versus nonfusion of the proximal thoracic curve in adolescent idiopathic scoliosis. Spine (Phila Pa 1976) 27: 2013-2020

7. Uzümcügil O, Atici Y, Ozturkmen Y, Yalcinkaya M, Caniklioglu M (2012) Evaluation of shoulder balance through growing rod intervention for early-onset scoliosis. J Spinal Disord Tech 25: 391-400.

8. Samy MA, Al Zayed ZS, Shaheen MF (2009) The effect of a vertical expandable prosthetic titanium rib on shoulder balance in patients with congenital scoliosis. J Child Orthop 3: 391-396.

9. Bess S, Akbarnia BA Thompson GH, Sponseller PD, Shah SA et al (2010) Complications of growing-rod treatment for early-onset scoliosis: analysis of one hundred and forty patients. J Bone Joint Surg Am 92: 2533-2543.

10. Thompson GH, Akbarnia BA, Campbell RM Jr (2007) Growing rod techniques in early-onset scoliosis. J Pediatr Orthop 27: 354-361.

11. Sankar WN, Acevedo DC, Skaggs DL (2010) Comparison of complications among growing spinal implants. Spine (Phila Pa 1976) 35: 2091-2096.

12. Thompson GH, Akbarnia BA, Kostial P, Poe-Kochert C, Armstrong DG, et al (2005) Comparison of single and dual growing rod techniques followed through definitive surgery: a preliminary study. Spine (Phila Pa 1976) 30: 2039-2044.

13. Akbarnia BA, Marks DS, Boachie-Adjei O, Thompson AG, Asher MA (2005) Dual growing rod technique for the treatment of progressive early-onset scoliosis: a multicenter study. Spine (Phila Pa 1976) 30: S46-57.

14. Akbarnia BA, Breakwell LM, Marks DS, McCarthy RE, Thompson AG, et al. (2008) Dual growing rod technique followed for three to eleven years until final fusion: the effect of frequency of lengthening. Spine (Phila Pa 1976) 33: 984-990. 